\title{
Comparative Study of Software Technologies for Learning Science in Colleges of Education- Ghana
}

\author{
Isaac Asare \\ Foso College of Education, Department of Science, P.O. Box 87, Assin Foso- Ghana, W/A
}

\begin{abstract}
Technology has now become integral part of our classrooms worldwide as one of the major means of delivering content to students. This study was to compare the use of some technology software for teaching and learning of science in the Colleges of Education in Ghana. It was conducted in six (6) Colleges of Education in the Central-Western zone. Questionnaire was used to collect data from the college students. The questionnaire consisted of seven (7) types of technology software which comprised of web-based software and non web-based software. Respondents responded according to their degree of acceptance of the use of each software for teaching and learning of science concepts. The findings were analysed using descriptive statistics. One hundred and twenty (120) teacher trainees were used for the study. The study showed that Social Media Platforms, E-mail, Google Classroom and WebQuest technology software were scarcely used for teaching and learning of science in the Colleges of Education in Ghana. It was however, indicated that Microsoft Excel, Microsoft Word and PowerPoint software were used often for teaching and learning of science.
\end{abstract}

Keywords: Technology tool, Non web-based technology, Web-based technology, Google classroom, WebQuest.

\subsection{Introduction}

Technological advances provide easier facilitation of and access to information, but technology does not change the message received by students, or the students' ability to grasp and retain information (Thurlow et al., 2004). Therefore, it is imperative students have a positive attitude and a basic understanding about technology to be successful in their adult lives (Young, 2008). If schools do not change along with society as far as technology is concerned, they will educate a group of students who do not have the technological skills to compete and succeed in higher education or in the job market, both nationally and internationally (Basset, 2005). It is not surprising therefore that most educational institutions all over the world have now accepted the use of technologies and incorporated them in their schools curriculum. Likewise, teachers who are implementers of a curriculum have also embraced them and use them in their instructions.

Nowadays, science tutors in the Colleges of Education in Ghana also integrate technology into their teaching. Yet, trainee students do not show motivation and interest to learn science. This might be as a result of the type of technology that science tutors in the Colleges of Education use to teach science concepts. In fact, for teacher trainees to recognise how meaningful and successful technology integration into teaching and learning is, science tutors in the Colleges of Education must be able to draw distinction among technology tools, web-based technology software and non-web-based technology software and know when and how to use each type. Research within technology shows that there has been little or no study on the use of web-based technology software for teaching and learning. This study therefore seeks to compare the use of some technology software for teaching and learning of science in the Colleges of Education in Ghana.

\subsection{Literature Review}

Web-conferencing software provides a virtual meeting space where users login simultaneously and communicate about a given topic (Laura et al., 2017), and is a type of technology software called web-based technology software. While each software application is unique, many share similar features such as audio, 
video, or instant messaging options for real-time communication; screen sharing, whiteboards, and digital pens for presentations and demonstrations; polls and quizzes for gauging comprehension or eliciting feedback; and breakout rooms for small group work (Bower, 2011; Hudson et al., 2012; Martin et al., 2012; McBrien et al. , 2009). Of the technologies included in this literature review, web-conferencing software most closely mimics the face-to-face classroom environment, providing a space where instructors and students can hear and see each other in real-time as typical classroom activities (i.e., delivering lectures, discussing course content, asking/answering questions) are carried out (Francescucci \& Foster, 2013; Hudson et al., 2012). Studies on web-conferencing software deployed Adobe Connect, Cisco WebEx, Horizon Wimba, or Blackboard Collaborate and made use of multiple features, such as screen sharing, instant messaging, polling, and break out rooms. In addition, most of the studies integrated webconferencing software into courses on a voluntary basis to supplement traditional instructional methods (Andrew et al., 2015; Armstrong \&Thornton, 2012; Francescucci \& Foster, 2013; Hudson et al., 2012; Martin et al., 2012; Wdowik, 2014). Existing studies on web-conferencing pertain to all three types of student engagement (Laura et al., 2017).

Studies on web-conferencing and behavioural engagement reveal mixed findings. For example, voluntary attendance in web-conferencing sessions ranged from 54 to 57\% (Andrew et al., 2015; Armstrong \& Thornton, 2012) and, in a comparison between a blended course with regular web-conferencing sessions and a traditional, face-to-face course, researchers found no significant difference in student attendance in courses. However, students in the blended course reported higher levels of class participation compared to students in the face-to-face course (Francescucci \& Foster, 2013). These findings suggest while webconferencing may not boost attendance, especially if voluntary, it may offer more opportunities for class participation, perhaps through the use of communication channels typically not available in a traditional, face-to-face course (e.g., instant messaging, anonymous polling) (Laura et al., 2017). Studies on webconferencing and interaction, another behavioural indicator, support this assertion. For example, researchers found that students use various features of web-conferencing software (e.g., polling, instant message, breakout rooms) to interact with peers and the instructor by asking questions, expressing opinions and ideas, sharing resources, and discussing academic content (Andrew et al., 2015; Armstrong \& Thornton, 2012; Hudson et al., 2012; Martin et al., 2012; Wdowik, 2014). Studies on web-conferencing and cognitive engagement are more conclusive than those for behavioural engagement, although are fewer in number (Laura et al, 2017). Findings suggest that students who participated in web-conferencing demonstrated critical reflection and enhanced learning through interactions with others (Armstrong \& Thornton, 2012), higher-order thinking (e.g., problem-solving, synthesis, evaluation) in response to challenging assignments (Wdowik, 2014), and motivation to learn, particularly when using polling features (Hudson et al., 2012). There is only one study examining how web-conferencing affects emotional engagement, although it is positive suggesting that students who participated in web-conferences had higher levels of interest in course content than those who did not (Francescucci \& Foster, 2013). One possible reason for the positive cognitive and emotional engagement findings may be that web-conferencing software provides many features that promote active learning (Laura et al., 2017). For example, whiteboards and breakout rooms provide opportunities for real-time, collaborative problem-solving activities and discussions (Laura et al., 2017). However, additional studies are needed to isolate and compare specific web-conferencing features to determine which have the greatest effect on student engagement (Laura et al., 2017).

In order to create a blog, one must compose content for an entry, which may include text, hyperlinks, graphics, audio, or video, publish the content online using a blogging application, and alert subscribers that new content is posted. Blogs may be informal and personal in nature or may serve as formal commentary in a specific genre, such as in politics or education (Coghlan et al, 2007). Fortunately, many blog applications are free, and many learning management systems (LMSs) offer a blogging feature that is seamlessly integrated into the online classroom (Laura et al, 2017). The ease of blogging has attracted attention from educators, who currently use blogs as an instructional tool for the expression of ideas, opinions, and experiences and for promoting dialogue on a wide range of academic topics (Garrity et al, 2014; Wang, 2008). Studies on blogs show consistently positive findings for many of the behavioural and emotional engagement indicators. For example, students reported that blogs promoted interaction with others, through greater communication and information sharing with peers (Chu et al, 2012; Ivala \& 
Gachago, 2012; Mansouri \& Piki, 2016), and analyses of blog posts show evidence of students elaborating on one another's ideas and sharing experiences and conceptions of course content (Sharma \& Tietjen, 2016). Blogs also contribute to emotional engagement by providing students with opportunities to express their feelings about learning and by encouraging positive attitudes about learning (Dos \& Demir, 2013; Chu et al., 2012; Yang \& Chang, 2012). For example, Dos and Demir (2013) found that students expressed prejudices and fears about specific course topics in their blog posts. In addition, Yang and Chang (2012) found that interactive blogging, where comment features were enabled, lead to more positive attitudes about course content and peers compared to solitary blogging, where comment features were disabled(Laura et al., 2017). The literature on blogs and cognitive engagement is less consistent (Laura et al., 2017). Some studies suggest that blogs may help students engage in active learning, problem-solving, and reflection (Chawinga, 2017; Chu et al., 2012; Ivala \& Gachago, 2012; Mansouri \& Piki, 2016), while other studies suggest that students' blog posts show very little evidence of higher-order thinking (Dos \& Demir, 2013; Sharma \& Tietjen, 2016). The inconsistency in findings may be due to the wording of blog instructions (Laura et al., 2017). Students may not necessarily demonstrate or engage in deep processing of information unless explicitly instructed to do so (Laura et al., 2017). Unfortunately, it is difficult to determine whether the wording of blog assignments contributed to the mixed results because many of the studies did not provide assignment details (Laura et al., 2017). However, studies pertaining to other technologies suggest that assignment wording that lacks specificity or requires low-level thinking can have detrimental effects on student engagement outcomes (Hou et al., 2015; Prestridge, 2014). Therefore, blog assignments that are vague or require only low-level thinking may have adverse effects on cognitive engagement (Laura et al., 2017).

A wiki is a web page that can be edited by multiple users at once (Nakamaru, 2012). Wikis have gained popularity in educational settings as a viable tool for group projects where group members can work collaboratively to develop content (i.e., writings, hyperlinks, images, graphics, media) and keep track of revisions through an extensive versioning system (Roussinos \& Jimoyiannis, 2013). Most studies on wikis pertain to behavioural engagement, with far fewer studies on cognitive engagement and none on emotional engagement (Laura et al., 2017). Studies pertaining to behavioural engagement reveal mixed results, with some showing very little enduring participation in wikis beyond the first few weeks of the course (Nakamaru, 2012; Salaber, 2014) and another showing active participation, as seen in high numbers of posts and edits (Roussinos \& Jimoyiannis, 2013). The most notable difference between these studies is the presence of grading, which may account for the inconsistencies in findings (Laura et al., 2017). For example, in studies where participation was low, wikis were ungraded, suggesting that students may need extra motivation and encouragement to use wikis (Nakamaru, 2012; Salaber, 2014). Findings regarding the use of wikis for promoting interaction are also inconsistent. In some studies, students reported that wikis were useful for interaction, teamwork, collaboration, and group networking (Camacho et al., 2016; Martínez et al., 2013; Morely, 2012; Calabretto \& Rao, 2011) and researchers found evidence of substantial collaboration among students (e.g., sharing ideas, opinions, and points of view) in wiki activity (Hewege \& Perera, 2013); however, Miller et al. (2012) found that only 58\% of students reported that wikis promoted collegiality among peers (Laura et al., 2017. The findings in the latter study were unexpected and may be due to design flaws in the wiki assignments (Laura et al., 2017). For example, the authors noted that wiki assignments were not explicitly referred to in face-to-face classes; therefore, this disconnect may have prevented students from building on interactive momentum achieved during out-of-class wiki assignments (Miller et al., 2012).

\subsection{Methodology}

\subsection{Research Design}

The study was a quantitative action research through a cross sectional survey. In this, structured questionnaire was the instrument used in order to enable collection of data from a large and diverse group of science students in the Colleges of Education in Ghana. The instrument was named Questionnaire for Colleges of Education Science Students (CoESS). The instrument consisted of two sections;' A' and 'B'. The section ' $A$ ' was about the demographic information of the respondents. The section ' $\mathrm{B}$ ' on the other hand, consisted of seven (7) types of technology software comprising of both non web-based software and web-based software for teacher trainees to indicate the extent to which each type of software is used in 
teaching and learning of science. Respondents were required to indicate their degree of acceptance or non acceptance of the use of a particularly type of technology software. The information obtained from the administration of the questionnaire was quantified and analysed using descriptive statistics; frequencies and their corresponding percentage values. Conclusion was drawn base on the data representing the students' response.

\subsection{Research Population}

The population was made up of all the six (6) public Colleges of Education in Central, Western and Western-North Regions of Ghana. These Colleges were Foso College of Education, Our Lady of Apostles (OLA) College of Education and Komenda College of Education in the Central Region. Holy Child College of Education from the Western Region with Echi College of Education and Wiawso College of Education College from the Western-North Regions.

\subsection{Sample and Sampling Procedure}

The sampled population was made up of one hundred and twenty (120) science students from the selected Colleges of Education.

The sampling techniques that were used were cluster sampling and purposive sampling techniques. Due to the geographical distribution of the population of the study (Colleges of Education) which is widely scattered across the length and breadth of Ghana, the researcher adapted cluster sampling to select Colleges which were confined in certain area of the country. That is, the Central, Western and Western-North Colleges which are all within the southern part of Ghana. Also, purposive sampling was used to select the sample to include a magnificent number of female science students.

\subsection{Instrumentation}

The instrument used for the study was a questionnaire. This instrument was made up of two sections; ' $A$ ' and 'B'. Section 'A' was about the demographics of respondents and section 'B' consisted of seven (7) types of technology software which comprised of both web-based and non web-based technology software.

In section 'B', each type of technology software was scored on a four-point scale. That is, "Very Often", "Often", "Sometimes" and "Not At All". A respondent could select from these scale depending upon one's degree of acceptance or non acceptance of the usage of a particularly type of technology software.

\subsection{Method of Data Analysis}

Types of technologies used for teaching and learning of science as they appeared in section ' $\mathrm{B}$ ' was analysed using descriptive statistics. (i.e., frequencies and their corresponding percentages for each type of technology software were calculated according to respondents' degree of acceptance or non acceptance of the use of each type of technology software from the scale of 'Very Often', 'Often', 'Sometimes' and 'Not At All'). The scales of 'Very Often' and 'Often' were combined to represent the total number of respondents who believed that a particular type of technology software was often used for teaching and learning of science whiles 'Sometimes' and 'Not At All' were also combined to give the total number of respondents who believed that a particular type of technology software was sometimes used for teaching and learning of science.

\subsection{Result}

Table 1: Response of Teacher Trainees about the Use of Technology Software for Teaching and Learning of Science in the Colleges of Education in Ghana

\begin{tabular}{|l|l|r|r|l|}
\hline $\begin{array}{l}\text { Type of technology } \\
\text { software }\end{array}$ & $\begin{array}{l}\text { Very Often } \\
\text { (VO) }\end{array}$ & $\begin{array}{l}\text { Often } \\
(\mathrm{O})\end{array}$ & $\begin{array}{l}\text { Sometimes } \\
\text { (S) }\end{array}$ & $\begin{array}{l}\text { Not At All } \\
\text { (NAA) }\end{array}$ \\
\hline Microsoft Excel & $22(18.3 \%)$ & $89(74.2 \%)$ & $3(2.5 \%)$ & $6(5.0 \%)$ \\
\hline $\begin{array}{l}\text { SocialMedia } \\
\text { Platform }\end{array}$ & $2(1.7 \%)$ & $11(9.2 \%)$ & $20(16.7 \%)$ & $87(72.5 \%)$ \\
\hline
\end{tabular}




\begin{tabular}{|l|l|c|c|c|}
\hline E-mail & $1(0.8 \%)$ & $5(4.2 \%)$ & $24(20.0 \%)$ & $90(75.0 \%)$ \\
Microsoft Word & $107(89.2 \%)$ & $13(10.8 \%)$ & $0(0 \%)$ & $0(0 \%)$ \\
\hline PowerPoint & $114(95.0 \%)$ & $6(5.0 \%)$ & $0(0 \%)$ & $0(0 \%)$ \\
Google Classroom & $0(0 \%)$ & $0(0 \%)$ & $10(8.3 \%)$ & $110(91.7 \%)$ \\
WebQuest & $0(0 \%)$ & $0(0 \%)$ & $2(1.7 \%)$ & $118(98.3 \%)$ \\
\hline
\end{tabular}

The descriptive statistics (Table 1) represents the dispositions of the teacher trainees who do science about the degree of usage of each type of technology software for teaching and learning of science in the colleges of education in Ghana.

\subsection{Findings}

From the Table 1, technology software, "Microsoft Excel" is a popular type of technology software in terms of its usage for teaching and learning of science. This is because $111(92.5 \%)$ of the students responded that it is often used for teaching and learning whiles only $9(7.5 \%)$ of them indicated that it is sometimes used for teaching and learning of science. "Social Media Platforms" and "E-mail" however, yielded responses that were opposite to that of the "Microsoft Excel". 107 (89.2\%) and 114 (95.0\%) were the number of students who responded that "Social Media Platforms" and "E-mail" technology software were sometimes used for teaching and learning of science respectively. And $13(10.9 \%)$ and $6(5.0 \%)$ were also the numbers who respectively indicated that "Social Media Platforms" and "E-mail" were often used for teaching and learning of science. In response to the extent of usage of "Microsoft Word" and "PowerPoint", all the students 120 (100\%) responded that they were often used for teaching and learning. None of them responded the otherwise to these types of technology software. Students' responses to "Google Classroom" and "WebQuest" were also completely opposite to that of "Microsoft Word" and "PowerPoint". That is, all the $120(100 \%)$ students indicated that "Google Classroom" and "WebQuest" technology software were sometimes used for teaching and learning of science concepts in the colleges of education. Meaning, none of them indicated that these technology software were used often for teaching and learning of science in the colleges of education.

The information obtained from the students about the level of usage of these types of technology software is a clear indication that 'Social Media Platform", "E-mail", "Google Classroom" and "WebQuest' software were the least popular among the technology software for teaching and learning of science whiles "Microsoft Excel", "Microsoft Word" and "PowerPoint" were the most use software for teaching and learning of science. Web-conferencing software provides a virtual meeting space where users login simultaneously and communicate about a given topic (Laura et al., 2017), and is a type of technology software called web-based technology software. And according to Francescucci and Foster (2013) and Hudson et al. (2012) web-conferencing software most closely mimics the face-to-face classroom environment, providing a space where instructors and students can hear and see each other in real-time as typical classroom activities (i.e., delivering lectures, discussing course content, asking/answering questions) are carried out. In respective of these advantages about the use of web-based software, the findings from this study are in contrast with these literatures as the result shows that web-based technology software are rarely used for teaching and learning of science in the colleges of education in Ghana.

\subsection{Conclusion}

The finding from this study showed that technology software is used for teaching and learning of science in the colleges of education in Ghana. It however, indicated that web-based technology

software is rarely used for teaching and learning of science. It is rather non web-based software that is frequently used for teaching and learning of science in the colleges of education in Ghana. 


\subsection{Recommendation}

In this $21^{\text {st }}$ century, almost all educational institutions on the globe are gradually moving from the traditional classroom environment (face-to-face instruction) to a virtual classroom (web-based instruction). Therefore colleges of education in Ghana especially those which were used in this study must do well and shift from the use of traditional classroom and start using a virtual classroom in order not to be left out in this globalisation campaign.

\section{Acknowledgement}

I am very much grateful to the Principals and Heads of Science Departments of the Colleges of Education used for this study for allowing me to use their colleges and departments. Also, I am thankful to the students who availed themselves and participated in this study.

\section{References}

1. Andrew, L., Maslin-Prothero, S., \& Ewens, B. (2015). Enhancing the online learning experience using virtual interactive classroom. Australian Journal of Advanced Nursing, 32(4), 22-31.

2. Armstrong, A., \& Thornton, N. (2012). Incorporating Brookfield's discussion techniques synchronously into asynchronous online courses. Quarterly Review of Distance Education, 13(1), 19.

3. Bassett, P. (2005). Reengineering schools for the 21st century. Phi Delta Kappa, 87(1), 76-78.

4. Bower, M. (2011). Redesigning a web-conferencing environment to scaffold computing students' creative design processes. Journal of Educational Technology and Society, 14(1), 27-42

5. Calabretto, J., \& Rao, D. (2011). Wikis to support collaboration of pharmacy students in medication management workshops -- a pilot project. International Journal of Pharmacy Education \& Practice, $8(2), 1-12$.

6. Camacho, M. E., Carrión, M. D., Chayah, M., \& Campos, J. M. (2016). The use of wiki to promote students' learning in higher education (Degree in Pharmacy). International Journal of Educational Technology in Higher Education, 13(1), 1-8.

7. Chawinga, W. D. (2017). Taking social media to a university classroom: teaching and learning using Twitter and blogs. International Journal of Educational Technology in Higher Education, 14 (3), 119.

8. Chu, S. K., Chan, C. K., \& Tiwari, A. F. (2012). Using blogs to support learning during internship. Computers \& Education, 58(3), 989-1000.

9. Coghlan, E., Crawford, J., Little, J., Lomas, C., Lombardi, M., Oblinger, D., \& Windham, C. (2007). ELI Discovery Tool: Guide to Blogging. Retrieved from http:// net.educause.edu/ ir/ library/pdf/ ELI8006.pdf.

10. Dos, B., \& Demir, S. (2013). The analysis of the blogs created in a blended course through the reflective thinking perspective. Educational Sciences: Theory and practice, 13 (2), 1335-1344.

11. Francescucci, A., \& Foster, M. (2013). The VIRI classroom: The impact of blended synchronous online courses on student performance, engagement, and satisfaction. Canadian Journal of Higher Education, 43 (3), 78-91.

12. Garrity, M. K., Jones, K., VanderZwan, K. J., de la Rocha, A. R., \& Epstein, I. (2014). Integrative review of blogging: Implications for nursing education. Journal of Nursing Education, 53 (7), 395 401.

13. Hewege, C. R., \& Perera, L. R. (2013). Pedagogical significance of wikis: Towards gaining effective learning outcomes. Journal of International Education in Business, 6(1), 51-70

14. Hou, H., Wang, S., Lin, P., \& Chang, K. (2015). Exploring the learner's knowledge construction and cognitive patterns of different asynchronous platforms: comparison of an online discussion forum and Facebook. Innovations in Education and Teaching International, 52(6), 610-620.

15. Hudson, T. M., Knight, V., \& Collins, B. C. (2012). Perceived effectiveness of web conferencing software in the digital environment to deliver a graduate course in applied behavior analysis. Rural Special Education Quarterly, 31(2), 27-39.

16. Ivala, E., \& Gachago, D. (2012). Social media for enhancing student engagement: The use of facebook and blogs at a university of technology. South Africa Journal of Higher Education, 26 (1), 152-167. 
17. Laura, A. S., Gary, J. B., Osama, A. M. \& Craig, M. (2017). Computer-based technology and student engagement: a critical review of the literature. International Journal of Educational Technology in Higher Education, 14(25), 337-350.

18. Mansouri, S. A., \& Piki, A. (2016). An exploration into the impact of blogs on students' learning: Case studies in postgraduate business education. Innovations in Education and Teaching International, 53(3), 260-273.

19. Martin, F., Parker, M. A., \& Deale, D. F. (2012). Examining interactivity in synchronous virtual classrooms. International Review of Research in Open and Distance Learning, 13(3), 227-261.

20. Martínez, A. A., Medina, F. X., Albalat, J. A. P., \& Rubió, F. S. (2013). Challenges and opportunities of 2.0 tools for the interdisciplinary study of nutrition: The case of the Mediterranean Diet wiki. International Journal of Educational Technology in Higher Education, 10(1), 210-225.

21. McBrien, J. L., Jones, P., \& Cheng, R. (2009). Virtual spaces: Employing a synchronous online classroom to facilitate student engagement in online learning. International Review of Research in Open and Distance Learning, 10(3), 1-17

22. Miller, A. D., Norris, L. B., \& Bookstaver, P. B. (2012). Use of wikis in pharmacy hybrid elective courses. Currents in Pharmacy Teaching \& Learning, 4(4), 256-261.

23. Morley, D. A. (2012). Enhancing networking and proactive learning skills in the first year university experience through the use of wikis. Nurse Education Today, 32(3), 261-266.

24. Nakamaru, S. (2012). Investment and return: Wiki engagement in a "remedial" ESL writing course. Journal of Research on Technology in Education, 44(4), 273-291

25. Roussinos, D., \& Jimoyiannis, A. (2013). Analysis of students' participation patterns and learning presence in a wiki-based project. Educational Media International, 50(4), 306-324.

26. Salaber, J. (2014). Facilitating student engagement and collaboration in a large postgraduate course using wiki-based activities. International Journal of Management Education, 12(2), 115-126.

27. Sharma, P., \& Tietjen, P. (2016). Examining patterns of participation and meaning making in student blogs: A case study in higher education. American Journal of Distance Education, 30(1), 2-13.

28. Thurlow, C., Lengel, L., \& Tomic, A. (2004). Computer mediated communication: Social interaction and the Internet. London: SAGE.

29. Wang, S. (2008). Blogs in Education: Encyclopedia of Multimedia Technology and Networking. Hershey: Information Sciences Reference.

30. Young, J. R. (2004). When good technology means bad teaching. The Chronicle of Higher Education, 51(12), 31-45. 